\title{
A CLASSIFICAÇÃO INTERNA DA TRIBO MYRTEAE, SOB O PONTO DE VISTA DA ANATOMIA DA MADEIRA ${ }^{1}$
}

\author{
SIDINEI RODRIGUES DOS SANTOS² JOSÉ NEWTON CARDOSO MARCHIORI ${ }^{3}$
}

\section{RESUMO}

No presente estudo é investigada a anatomia da madeira de 15 gêneros e 34 espécies de Myrteae nativas no Rio Grande do Sul sob o ponto de vista taxonômico. Observou-se uma grande homogeneidade estrutural entre as espécies, reflexo do elevado número de caracteres anatômicos compartilhados e da baixa variabilidade apresentada pelos mesmos. Nenhum gênero pode ser identificado com base na anatomia da madeira, com exceção de Myceugenia. As espécies, todavia, podem ser separadas, embora nem sempre. Também não é possível reconhecer categorias taxonômicas inferiores à tribo. A falta de caracteres anatômicos exclusivos para os gêneros e grupos superiores limita a atuação da anatomia da madeira em discussões taxonômicas na tribo Myrteae.

Palavras-chave: Myrtaceae, Myrteae, Anatomia da Madeira, Taxonomia.

\section{ABSTRACT}

[The internal classification of Myrteae, according to the wood anatomy point of view].

The wood anatomy of 34 species native in Rio Grande do Sul state, Brazil related to 15 distinct genera of Myrteae, are presently studied under the taxonomic point of view. A great structural homogeneity was observed, reflecting the high number of shared anatomical features and the low variability usually observed. None genera could be identified based on wood anatomy, with the only exception of Myceugenia; the species, however, can be separated, but not always. Infra-tribe taxonomic categories can't also be identified. The lack of specific anatomical features to genera and higher groups limits the use of wood anatomy in taxonomic studies of Myrteae.

Key words: Myrtaceae, Myrteae, Wood Anatomy, Taxonomy.

\section{INTRODUÇÃO}

A família Myrtaceae Adans. compreende cerca de 150 gêneros e 3600 espécies de árvores e arbustos, distribuídos principalmente na região temperada da Austrália, América tropical e subtropical (Govaerts et al., 2008). No Brasil ocorrem aproximadamente 25 gêneros e 1200 espécies de Mirtáceas, todas da tribo Myrteae ou subfamília Myrtoideae (Landrum \& Kawasaki, 1997).

\footnotetext{
1 Recebido para publicação em 30-09-2011 e aceito para publicação em 15-10-2011.

2 Biólogo. Bolsista (CNPq - Brasil), doutorando do Programa de Pós-Graduação em Engenharia Florestal, Departamento de Ciências Florestais, Universidade Federal de Santa Maria. CEP 97105-900. Santa Maria, RS, Brasil.sthurt.bio@gmail.com

3 Engenheiro Florestal, Dr. Bolsista de Produtividade em Pesquisa (CNPq - Brasil). Professor Titular do Departamento de Ciências Florestais, Universidade Federal de Santa Maria. Santa Maria, RS, Brasil.
}

Trata-se de uma das famílias mais complexas sob o ponto de vista taxonômico, fato comprovado pelas inúmeras alterações na classificação interna, sofridas desde os tempos de De Candolle (1828). Tal complexidade resulta não apenas do tamanho do grupo e da grande semelhança morfológica entre os diferentes gêneros e espécies, mas, principalmente, da falta de estudos taxonômicos mais abrangentes e da adoção de caracteres morfológicos considerados críticos para a sua delimitação (Barroso, 1991; Landrum \& Kawasaki, 1997).

Tradicionalmente são reconhecidas duas subfamílias, diferenciadas pela filotaxia e por caracteres morfológicos de frutos e sementes (Niedenzu, 1893): Leptospermoideae, reunindo espécies de folhas alternas, frutos secos e sementes diminutas; e Myrtoideae, com espécies de folhas opostas, frutos carnosos e sementes grandes. Schmid (1980) considerou a exis- 


\begin{tabular}{|c|c|c|c|}
\hline Subtribo & Myrciinae O. Berg & Eugeniinae 0 . Berg & Myrtiinae O. Berb \\
\hline 垴 命 & $\begin{array}{l}\text { "Subtribo Myrcioideae" } \\
\text { Calyptranthes, Gomidesia, } \\
\text { Marlierea, Myrceugenia, } \\
\text { Myrcia, Aulomyrcia (Myrcia), } \\
\text { Calyptromyrcia (Myrcia), } \\
\text { Cerquierea (Gomidesia), } \\
\text { Eugeniopsis (Marlierea) e } \\
\text { Rubachia (Marlierea) }\end{array}$ & $\begin{array}{c}\text { "Subtribo Eugenioideae" } \\
\text { Calycorectes, Caryophyllus, Eugenia, } \\
\text { Hexachlamys, Mytranthes, Myrcianthes, } \\
\text { Myrciaria, Schizocalyx (Calycorectes), } \\
\text { Siphoneugena, Syzygium, Aulocarpus } \\
\text { (Mouriri-Melastomataceae), Jambosa } \\
\text { (Syzygium), Phyllocalix (Eugenia)e } \\
\text { Stenocalyx (Eugenia) }\end{array}$ & $\begin{array}{c}\text { "Subtribo Pimentoideae" } \\
\text { Blepharocalyx, Calycolpus, Myrtus e } \\
\text { Psidium. } \\
\text { Abbevillea, Acrandra, Britoae } \\
\text { Lacerdaea (Campomanesia), } \\
\text { Campomanesia, Pseudocaryophyllus } \\
\text { (Pimenta) }\end{array}$ \\
\hline \multirow{4}{*}{ 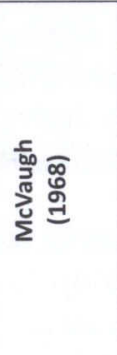 } & \multirow{4}{*}{$\begin{array}{c}\text { "gêneros Mircióides" } \\
\text { Calyptranthes, Gomidesia, } \\
\text { Marlierea, Myrceugenia, } \\
\text { Myrcia, Nothomyrcia } \\
\text { (Myrceugenia) }\end{array}$} & \multirow{2}{*}{$\begin{array}{l}\text { "gêneros Eugenióides" } \\
\text { Calycorectes, Eugenia, Hexachlamys, } \\
\text { Myrciaria, Plinia, Siphoneugena }\end{array}$} & $\begin{array}{l}\text { "Campomanesia e gêneros afins" } \\
\text { Campomanesia, Blepharocalyx, } \\
\text { Temu e Paivea (Campomanesia) }\end{array}$ \\
\hline & & & \multirow{2}{*}{$\begin{array}{c}\text { "Psidium e gêneros afins" } \\
\text { Calycolpus, Myrtus, Myrteola, } \\
\text { Psidium, Ugni, Amomyrtus (Myrtus) } \\
\text { e Amomyrtella (Myrtus) }\end{array}$} \\
\hline & & $\begin{array}{c}\text { "Myrcianthes e gêneros afins" } \\
\text { Legrandia, Luma, Myrcianthes, Pseudamomis } \\
\text { e Reichea }\end{array}$ & \\
\hline & & & Pseudocaryophyllus e Pimenta \\
\hline \multirow{2}{*}{ 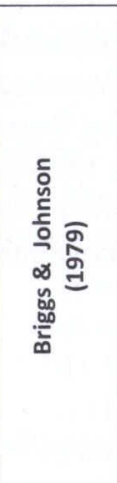 } & \multirow{2}{*}{$\begin{array}{l}\text { "aliança Myrcia" } \\
\text { Calyptranthes, Gomidesia, } \\
\text { Marlierea, Mytranthes, } \\
\text { Myrceugenia, Myrcia e } \\
\text { Nothomyrcia (Myrceugenia) }\end{array}$} & \multirow{2}{*}{$\begin{array}{c}\text { "aliança Eugenia" } \\
\text { Acreugenia, Calycorectes, Eugenia, } \\
\text { Hexachlamys, Luma (Myrceugenella), } \\
\text { Myrcianthes, Myrciaria, Paramyrciaria, } \\
\text { Plinia, "Pliniopsis", Reichea (Aspidog enia) e } \\
\text { Siphoneugena }\end{array}$} & $\begin{array}{c}\text { "aliança Myrtus" } \\
\text { Acca, Amomyrtella, Amomyrtus, } \\
\text { Calycolpus, Feijoa (Acca), Mosiera, } \\
\text { Myrrhinium, Myrteola, Myrtus, } \\
\text { Pimenta, Pseudocaryophyllus } \\
\text { (Pimenta), Psidiopsis (Calycolpus), } \\
\text { Psidium e Ugni }\end{array}$ \\
\hline & & & $\begin{array}{l}\text { "aliança Cryptorhiza" } \\
\text { Blepharocalyx, Campomanesia, } \\
\text { Cryptorhiza, Legrandia } \\
\text { (Campomanesia), Marlieriopsis } \\
\text { (Blepharocalyx), Paivea } \\
\text { (Campomanesia) e Pilidiostigma }\end{array}$ \\
\hline 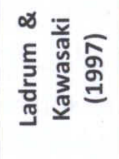 & $\begin{array}{l}\text { Calyptranthes, Myrcia } \\
\text { (incluindo Marlierea e } \\
\text { Gomidesia) e Myrceugenia }\end{array}$ & $\begin{array}{c}\text { Eugenia (incluindo Calycorectes e } \\
\text { Hexachlamys), Myrcianthes, Myrciaria } \\
\text { (incluindo Paramyrciaria), Neomitranthes, } \\
\text { Plinia e Siphoneugena }\end{array}$ & $\begin{array}{l}\text { Acca, Accara, Blepharocalyx, } \\
\text { Calycolpus, Campomanesia, } \\
\text { Mosiera, Myrrhinium, Pimenta, } \\
\text { Psidium e Ugni }\end{array}$ \\
\hline
\end{tabular}

QUADRO 1 - Classificação da Tribo Myrteae, segundo os principais autores (Adaptado de COSTA, 2004). Os nomes entre parênteses são as atuais sinonímias.

tência de outras duas subfamílias: Chamelaucioideae (composta por alguns gêneros de Leptospermoideae de frutos drupáceos secos) e Psiloxyloideae (com um gênero monotípico da antiga família Psiloxylaceae (Psiloxylon), de frutos bacóides e filotaxia alterna); Johnson \& Briggs (1984), no entanto, admitem apenas a existência da primeira delas.
A circunscrição dos grandes grupos infrafamiliares em Myrtaceae foi melhor esclarecida a partir do desenvolvimento de estudos filogenéticos baseados em dados morfológicos, anatômicos e/ou moleculares, nas últimas décadas (Johnson \& Briggs, 1984; Wilson et al., 2001, 2005). Tais estudos têm demonstrado que as tradicionais subfamílias não for- 
mam um grupo natural e que os frutos carnosos, base para distinção das mesmas, teriam surgido independentemente, por diversas vezes, na trajetória evolutiva da família, devendo esta classificação, portanto, ser abandonada. Atualmente são reconhecidas duas subfamílias (Psiloxyloideae e Myrtoideae) e 17 tribos, 15 das quais pertencentes a este último grupo (Myrtoideae), inclusive a tribo Myrteae, que inclui todos os taxa de frutos carnosos, nativos na América do Sul (Wilson et al., 2005).

A classificação interna da tribo Myrteae também sofreu modificações. $\mathrm{O}$ arranjo dos gêneros em três subtribos, como proposto por Berg (1855-56; 1857-59), não é corroborado em estudos taxonômicos mais recentes (Quadro 1), incluindo os filogenéticos, que apontam a existência de pelos menos seis agrupamentos genéricos dentro da referida tribo (Lucas et al., 2005; Costa, 2009).

Apesar dos problemas na delimitação dos grupos infrafamiliares, é incontestável a monofilia da família como um todo, assim como da tribo Myrteae, segundo a interpretação destes mesmos autores. Das subtribos propostas por Berg, apenas as Myrciinae formam um grupo natural, excluindo Myrceugenia. O correto posicionamento deste gênero, todavia, assim como de Blepharocalyx e Luma, segue indefinido.

A redução dos gêneros Hexachlamys e Calycorectes em Eugenia, de Paramyrciaria em Myrciaria, e de Gomidesia em Myrcia (Landrum \& Kawasaki, 1997), serve, igualmente, embora ainda não completamente estabelecida, para testemunhar a instabilidade taxonômica ainda observada na família.

O breve histórico taxonômico acima exposto demonstra as numerosas modificações no arranjo da família, que aguardam, todavia, por confirmação. O presente trabalho, que investiga a anatomia da madeira de 15 gêneros e 34 espécies nativas de Myrtaceae, foi desenvolvido, justamente, visando este objetivo. Como enfatizado por Barroso (1991), apenas com um levantamento cuidadoso das espécies em cada região, aliado a estudos de biossistemática, será possível um maior esclarecimento acerca da taxonomia de Myrtaceae.

\section{REVISÃO DA LITERATURA}

Estudos envolvendo anatomia da madeira em Myrtaceae são escassos, mesmo os puramente descritivos. Ainda mais raros na família são os trabalhos de Anatomia Sistemática.

Record \& Hess (1949) e Metcalfe \& Chalk (1972) fornecem, respectivamente, uma caracterização geral da família, com alguns comentários de cunho taxonômico. De acordo com o primeiro deles, a variabilidade em Eugenia, no tocante à aparência, propriedades e estrutura da madeira, é tão grande quanto a que se observa entre os diferentes gêneros de Myrtoideae; no gênero Myrceugenia, no entanto, a anatomia difere significativamente da observada em outros grupos. Metcalfe \& Chalk (1972), por sua vez, salientam, em notas taxonômicas, que não existem diferenças consistentes entre as subfamílias e que as diferenças entre espécies de um mesmo gênero são, por vezes, pouco marcadas.

Détienne \& Jacquet (1983) investigaram a anatomia da madeira de 8 gêneros e 14 espécies de Myrtaceae da Amazônia, com vistas ao reconhecimento de características úteis à separação e identificação dos taxa. O estudo demonstrou ser difícil a separação dos gêneros na família, devido tanto a homogeneidade entre gêneros distintos, quanto à heterogeneidade entre espécies de um mesmo gênero. Dias-Leme et al. (1995), em estudo anatômico envolvendo 31 espécies e quatro gêneros da subtribo Myrciinae (Calyptranthes, Gomidesia, Marlierea e Myrcia), chegaram à conclusão semelhante. De acordo com os autores, nenhuma característica, isoladamente ou em combinação, é consistentemente distribuída dentro de cada gênero para ter valor diagnóstico a este nível taxonômico.

Cabe mencionar, ainda, o trabalho realizado por Vliet \& Baas (1984) sobre as Myrtales. Neste estudo, além da caracterização anatômica, foram discutidas as tendências de especializa- 
ção e relacionamentos filogenéticos dentro da ordem. No caso das Myrtaceae, observou-se predomínio de características primitivas na madeira (vasos solitários; placas de perfuração escalariformes; fibrotraqueídeos; traqueídeos vasicêntricos; parênquima apotraqueal; e raios heterogêneos), com algumas exceções, como no caso de Eucalyptus, que tem estrutura anatômica mais especializada (vasos em múltiplos; fibras libriformes, por vezes septadas; parênquima paratraqueal aliforme a confluente; e pontoações raio-vasculares e parênquimo-vasculares grandes e simples). Apesar da abrangência, não constam discussões sobre a classificação dos grupos infrafamiliares no referido estudo.

\section{MATERIAL E MÉTODOS}

No presente estudo é analisada a anatomia da madeira de 34 espécies, pertencentes a 15 gêneros de Myrtaceae, de ocorrência natural no Rio Grande do Sul (Tabela 1). Estes números representam cerca de um terço e $80 \%$, respectivamente, do contingente do Estado, que totaliza 19 gêneros e 109 espécies (Marchiori \& Sobral, 1997; Sobral, 2003).

Os dados qualitativos e quantitativos da estrutura anatômica das espécies, que constituem a base do presente estudo, encontram-se resumidos nas Tabelas 1 e 2, e foram colhidos, basicamente, de publicações anteriores, de um ou mais dos autores.

Para maiores detalhes acerca da estrutura anatômica das espécies, recomendam-se as publicações originais: Marchiori (1984a,b,c, 1998), Marchiori \& Brum (1997), Marchiori \& Muñiz (1987a,b, 1988), Marchiori \& Santos (2009a,b,c 2010a,b,c) e Santos \& Marchiori (2009a,b,c,d 2010a,c,d,e,f,g, 2011a,b,c). Eventualmente, podem ser observadas discrepâncias entre os caracteres aqui relacionados e as descrições originais, motivadas por uma análise mais minuciosa do mesmo material, feita, sempre, com o intuito de maior aproximação com a realidade.
ANÁLISE DA ESTRUTURA ANATÔMICA

Como se pode observar nas Tabelas 1 e 2, a variabilidade observada na maioria das características anatômicas é baixa, havendo, ao mesmo tempo, um grande número de caracteres anatômicos compartilhados entre as espécies, $o$ que implica em uma grande homogeneidade estrutural, em consonância com o observado por Metcalfe \& Chalk (1972), Détienne \& Jacquet (1983) e, inclusive, para a morfologia externa (Barroso, 1991; Landrum \& Kawasaki, 1997). Algumas características têm ocorrência generalizada, caso de poros solitários, de placas de perfuração simples, de apêndices e ornamentações, de pontoações intervasculares alternas, de parênquima apotraqueal seriado, difuso e difusoem-agregados, de raios heterogêneos, de fibras com pontoações areoladas e de células radiais com paredes disjuntas (Figura 1). A presença constante deste conjunto de características favorece a interpretação das análises filogenéticas que consideram a tribo Myrteae como um grupo natural (Lucas et al., 2005; Costa, 2009).

Nenhuma característica anatômica serve, isoladamente ou em conjunto, para a identificação de gêneros, com exceção de Myrceugenia, que é caracterizado pela combinação de pontoações horizontalmente estendidas, espessamentos espiralados e placas de perfuração múltiplas (Figura 2); esta última, todavia, nem sempre observada na madeira (Tabela 1). Este resultado concorda plenamente com o obtido por DiasLeme et al. (1995), levando-se em conta que os mesmos não incluíram Myrceugenia em seus estudos, apesar de tratar-se de um verdadeiro representante da subtribo Myrciinae.

Détienne \& Jacquet (1983) também encontraram dificuldade na separação dos gêneros, devido tanto à homogeneidade estrutural dos mesmos, como à heterogeneidade entre espécies de um mesmo gênero. A singularidade de Myrceugenia, todavia, não constitui novidade. Record \& Hess (1949) já haviam registrado, 
TABELA 1 - Principais características qualitativas das madeiras investigadas.

\begin{tabular}{|c|c|c|c|c|c|c|c|c|c|c|c|}
\hline \multirow{2}{*}{ Espécie } & \multirow{2}{*}{ Poros } & \multicolumn{4}{|c|}{ Vasos } & \multicolumn{2}{|c|}{ P. axial } & \multicolumn{2}{|c|}{ Raios } & \multirow{2}{*}{$\begin{array}{c}\text { Fibras } \\
\text { esp }\end{array}$} & \multirow{2}{*}{$\begin{array}{c}\text { Máculas } \\
\text { medulares }\end{array}$} \\
\hline & & arj & $p p$ & $e e$ & prv & arj & $\mathrm{cr}$ & $m / c$ & cont & & \\
\hline Acca sellowiana & $d$ & sl & s & - & siv & da & + & $m>c$ & - & e & - \\
\hline Blepharocalyx salicifolius & $d$ & sl & s & - & $\operatorname{siv}$ & da & $-1+$ & v & - & $\mathrm{e}$ & $+1-$ \\
\hline Calyptranthes concinna & $d$ & sl & s & - & $\operatorname{siv}$ & da & - & $m>c$ & $-1+$ & e & + \\
\hline C. tricona & $d$ & sl & s & - & siv & $\mathrm{fd}$ & - & $m>c$ & - & $\mathrm{e}$ & - \\
\hline Campomanesia aurea & $d$ & sl & $s$ & - & siv & da & - & $m<c$ & - & e & - \\
\hline C. guazumifolia & $d$ & sl & s & - & siv & da & - & $m<c$ & + & e & + \\
\hline C. rhombea & d & sl & $s$ & - & siv & da & - & $m<c$ & - & $\mathrm{e}$ & - \\
\hline C. xanthocarpa & d & sl & $s$ & - & siv & da & - & $m<c$ & - & e & - \\
\hline Eugenia burkartiana & $d$ & sl & $\mathrm{s}$ & - & siv & da & + & $m>c$ & - & me & - \\
\hline E. hiemalis & d & sl & s & - & siv & $\mathrm{fd}$ & + & $m>c$ & - & e & - \\
\hline E. involucrata & $d$ & sl & s & + & siv & da & + & $\mathrm{m}>\mathrm{c}$ & - & $\mathrm{e}$ & - \\
\hline E. mansoi & d & sl & $s$ & - & $\operatorname{siv}$ & $\mathrm{fd}$ & + & $m>c$ & - & $\mathrm{e} / \mathrm{me}$ & - \\
\hline E. rostrifolia & d & $\mathrm{sl} / \mathrm{mt}$ & s & - & siv & $f x$ & + & $\mathrm{m}<\mathrm{c}$ & - & me & - \\
\hline E. schuechiana & $d$ & sl & s & - & siv & $\mathrm{da} / \mathrm{fd}$ & + & $m>c$ & + & e & - \\
\hline E. uniflora & d & sl & s & - & siv & $f x$ & + & $m>c$ & - & me & - \\
\hline E. uruguayensis & $d$ & sl & s & - & siv & da & + & $\mathrm{m}<\mathrm{c}$ & - & me & + \\
\hline Gomidesia palustris & d & sl & s & - & siv & d & - & $\mathrm{m}<\mathrm{c}$ & + & $f$ & - \\
\hline Hexachlamys edulis & d & sl & $\mathrm{s}$ & - & siv & $f x$ & + & $m>c$ & + & e & - \\
\hline Myrceugenia euosma & d & sl & $\mathrm{s} / \mathrm{m}$ & + & $h z$ & da & - & $m>c$ & - & e & - \\
\hline M. glaucescens & d & sl & $\mathrm{s} / \mathrm{m}$ & + & hz & da & - & $m>c$ & - & e & - \\
\hline M. miersiana & $d$ & sl & $\mathrm{s} / \mathrm{m}$ & + & $h z$ & da & - & $m>c$ & - & e & - \\
\hline M. myrtoides & d & sl & $\mathrm{s}$ & + & hz & da & - & $m>c$ & + & e & - \\
\hline Myrcia bombycina & $d$ & sl & $s$ & - & $\operatorname{siv}$ & da & - & $v$ & + & $f$ & + \\
\hline M. selloi & d & sl & $\mathrm{s}$ & - & siv & da & + & $m>c$ & $-1+$ & me & - \\
\hline Myrcianthes cisplatensis & d & sl & $s$ & + & $\operatorname{siv}$ & da & - & $m>c$ & $-1+$ & e/me & $+1-$ \\
\hline M. gigantea & d & sl & $\mathrm{s}$ & + & siv & da & - & $m>c$ & + & fe & + \\
\hline M. pungens & d & sl & $s$ & - & siv & $f x$ & $-/+$ & $v$ & - & $\mathrm{e} / \mathrm{me}$ & $+/-$ \\
\hline Myrciaria cuspidata & d & sl & $\mathrm{s}$ & - & siv & da & - & $m>c$ & + & e & + \\
\hline M. tenella & $d$ & sl & $s$ & - & $\operatorname{siv}$ & da & - & $m>c$ & + & $\mathrm{e} / \mathrm{me}$ & - \\
\hline Myrrhinium atropurpureum & d & sl & $s$ & - & siv & $\mathrm{da} / \mathrm{fd}$ & + & $m>c$ & $-1+$ & me & $+/-$ \\
\hline Plinia rivularis & d & $\mathrm{sl} / \mathrm{mt}$ & $s$ & - & $\operatorname{siv}$ & da & + & $m>c$ & - & me & + \\
\hline P. trunciflora & d & sl & $s$ & - & siv & da & + & $m<c$ & - & e & + \\
\hline Psidium cattleianum & d & $\mathrm{sl} / \mathrm{mt}$ & s & - & siv & da & + & $m>c$ & - & e & $+/-$ \\
\hline Siphoneugena reitzii & d & sl & $s$ & - & siv & da & - & $m<c$ & - & e & + \\
\hline
\end{tabular}

poros $=$ porosidade $(d$ difusa $) ; \operatorname{arj}=$ arranjo $(s l$ solitários; $m t$ múltiplos $) ; \mathrm{pp}=$ placas de perfuração $(s$ simples; $m$ múltiplas); $e e=$ espessamentos espiralados; $p r v=$ pontoações raio-vasculares ( $\operatorname{siv}$ semelhantes às intervasculares; $h z$ horizontais); $d a=$ difuso-em-agregados; $f x=$ faixas contínuas; $f d=$ faixas descontínuas e estreitas; $d=$ difuso; $c r=$ cristais; $m / c=$ altura das margens em relação ao corpo central ( $>$ maior; $<$ menor; $v$ variável); cont $=$ conteúdo abundante; $e s p=$ espessura da parede ( $f$ finas; $e$ espessas; $m e$ muito espessas); - = caráter ausente; $+=$ caráter presente. Observação: no arranjo do parênquima axial, considerou-se apenas o tipo predominante na madeira. 
TABELA 2 - Principais características quantitativas das madeiras investigadas.

\begin{tabular}{|c|c|c|c|c|c|c|c|c|c|c|c|c|c|c|}
\hline \multirow{3}{*}{ Espécie } & \multirow{2}{*}{\multicolumn{4}{|c|}{ Vasos }} & \multirow{2}{*}{\multicolumn{2}{|c|}{ P. axial }} & \multicolumn{7}{|c|}{ Raios } & \multirow{3}{*}{$\begin{array}{c}\text { Fibras } \\
\text { C }\end{array}$} \\
\hline & & & & & & & & & altiss & & & & & \\
\hline & $f r$ & $d$ & c & dpiv & $h$ & h1 & $L$ & $h$ & h1 & $m$ & $h$ & h1 & $f r$ & \\
\hline Acca sellowiana & 266 & 33 & 444 & 5,1 & $3-6$ & 414 & 2 & 14 & 160 & $<5$ & 6 & 98 & 15 & 744 \\
\hline Blepharocalyx salicifolius & 90 & 38 & 471 & 5,4 & $2-8$ & 445 & 2 & 15 & 208 & $<5$ & 8 & 108 & 19 & 926 \\
\hline Calyptranthes concinna & 11 & 58 & 510 & 6,3 & $4-8$ & 526 & 2 & 22 & 344 & $>4$ & 10 & 241 & 24 & 999 \\
\hline C. tricona & 17 & 70 & 487 & 5,8 & $2-8$ & 431 & 3 & 23 & 406 & $<5$ & 12 & 239 & 30 & 1064 \\
\hline Campomanesia aurea & 51 & 28 & 361 & 4,9 & $2-4$ & 294 & 3 & 16 & 213 & $<5$ & 8 & 114 & 19 & 717 \\
\hline C. guazumifolia & 93 & 49 & 551 & 4,3 & $3-8$ & 442 & 3 & 22 & 271 & $<5$ & 9 & 140 & 16 & 1168 \\
\hline C. rhombea & 17 & 70 & 392 & 5,9 & $2-4$ & 404 & 3 & 20 & 244 & $<5$ & 6 & 103 & 13 & 1140 \\
\hline C. xanthocarpa & 18 & 78 & 423 & 4,5 & $2-8$ & 458 & 4 & 30 & 277 & $<5$ & 13 & 144 & 13 & 1246 \\
\hline Eugenia burkartiana & 46 & 25 & 565 & 4,7 & $4-9$ & 547 & 2 & 26 & 376 & $>4$ & 15 & 216 & 26 & 1077 \\
\hline E. hiemalis & 26 & 61 & 448 & 4,8 & $2-10$ & 462 & 3 & 17 & 281 & $<5$ & 7 & 184 & 19 & 1086 \\
\hline E. involucrata & 21 & 58 & 582 & 5,4 & $4-9$ & 583 & 2 & 18 & 275 & $<5$ & 10 & 168 & 16 & 1226 \\
\hline E. mansoi & 143 & 30 & 592 & 4,4 & $4-11$ & 581 & 2 & 24 & 365 & $>4$ & 14 & 257 & 23 & 990 \\
\hline E. rostrifolia & 134 & 42 & 514 & 4,2 & $4-13$ & 547 & 3 & 21 & 260 & $<5$ & 12 & 172 & 20 & 995 \\
\hline E. schuechiana & 20 & 51 & 690 & 5,5 & $4-10$ & 710 & 2 & 38 & 465 & $<5$ & 7 & 258 & 18 & 1495 \\
\hline E. uniflora & 86 & 37 & 486 & 4,7 & $3-9$ & 402 & 2 & 20 & 265 & $>4$ & 13 & 162 & 20 & 888 \\
\hline E. uruguayensis & 50 & 48 & 621 & 4,7 & $2-8$ & 538 & 3 & 19 & 363 & $<5$ & 6 & 205 & 19 & 1236 \\
\hline Gomidesia palustris & 44 & 58 & 681 & 5,4 & $3-8$ & 556 & 5 & 60 & 1097 & $>4$ & 20 & 522 & 18 & 1246 \\
\hline Hexachlamys edulis & 52 & 52 & 526 & 5,4 & $4-14$ & 550 & 2 & 15 & 261 & $<5$ & 8 & 167 & 19 & 1154 \\
\hline Myrceugenia euosma & 254 & 29 & 541 & 9,6 & $3-8$ & 432 & 3 & 36 & 507 & $>4$ & 28 & 302 & 29 & 936 \\
\hline M. glaucescens & 116 & 40 & 596 & 9,5 & $4-8$ & 592 & 3 & 25 & 425 & $>4$ & 17 & 259 & 23 & 1083 \\
\hline M. miersiana & 201 & 35 & 460 & 12,1 & $4-8$ & 592 & 3 & 33 & 646 & $>4$ & 26 & 493 & 24 & 1163 \\
\hline M. myrtoides & 140 & 43 & 594 & 6,8 & $4-8$ & 498 & 2 & 24 & 323 & $>4$ & 9 & 244 & 19 & 959 \\
\hline Myrcia bombycina & 34 & 58 & 461 & 7,5 & $2-5$ & 432 & 3 & 21 & 320 & $<5$ & 12 & 223 & 23 & 893 \\
\hline M. selloi & 25 & 46 & 606 & 5,7 & $2-8$ & 680 & 2 & 22 & 428 & $>5$ & 17 & 295 & 21 & 1364 \\
\hline Myrcianthes cisplatensis & 178 & 25 & 441 & 5,2 & $4-8$ & 439 & 3 & 20 & 254 & $<5$ & 11 & 142 & 20 & 899 \\
\hline M. gigantea & 125 & 28 & 496 & 5,4 & $4-8$ & 552 & 3 & 15 & 253 & $<5$ & 8 & 143 & 17 & 924 \\
\hline M. pungens & 136 & 37 & 505 & 4,9 & $2-16$ & 442 & 3 & 19 & 208 & $<5$ & 9 & 115 & 20 & 1023 \\
\hline Myrciaria cuspidata & 131 & 29 & 439 & 3,8 & $3-8$ & 407 & 2 & 25 & 302 & $>4$ & 12 & 176 & 29 & 937 \\
\hline M. tenella & 178 & 30 & 469 & 4,5 & $3-7$ & 424 & 2 & 25 & 229 & $>4$ & 6 & 98 & 28 & 1013 \\
\hline Myrhinium atropurp. & 54 & 42 & 503 & 5,7 & $3-8$ & 496 & 2 & 18 & 273 & $>4$ & 13 & 197 & 19 & 977 \\
\hline Plinia rivularis & 89 & 48 & 535 & 5,2 & $7-11$ & 528 & 3 & 23 & 319 & $>5$ & 9 & 164 & 21 & 1316 \\
\hline P.trunciflora & 140 & 25 & 476 & 4,1 & $2-8$ & 355 & 3 & 21 & 181 & $<5$ & 4 & 83 & 19 & 969 \\
\hline Psidium cattleianum & 49 & 43 & 809 & 4,5 & $2-9$ & 764 & 2 & 20 & 360 & $<5$ & 9 & 221 & 16 & 1570 \\
\hline Siphoneugena reitzii & 131 & 36 & 407 & 3,9 & $2-4$ & 287 & 3 & 15 & 193 & $<5$ & 6 & 113 & 22 & 1023 \\
\hline
\end{tabular}

$f r=$ frequência $\left(\operatorname{vasos} / \mathrm{mm}^{2} ;\right.$ raios $\left./ \mathrm{mm}\right) ; d=$ diâmetro; $c=$ comprimento; $d$ piv = diâmetro de pontoações intervasculares; $h=$ altura máxima (células); $h l=$ altura (micrômetros); $L=$ largura máxima (células); $m=$ altura das margens unisseriadas (células). $<=$ menor; $>=$ maior. Observação: os números correspondem aos valores médios, exceto quando especificado o contrário. 


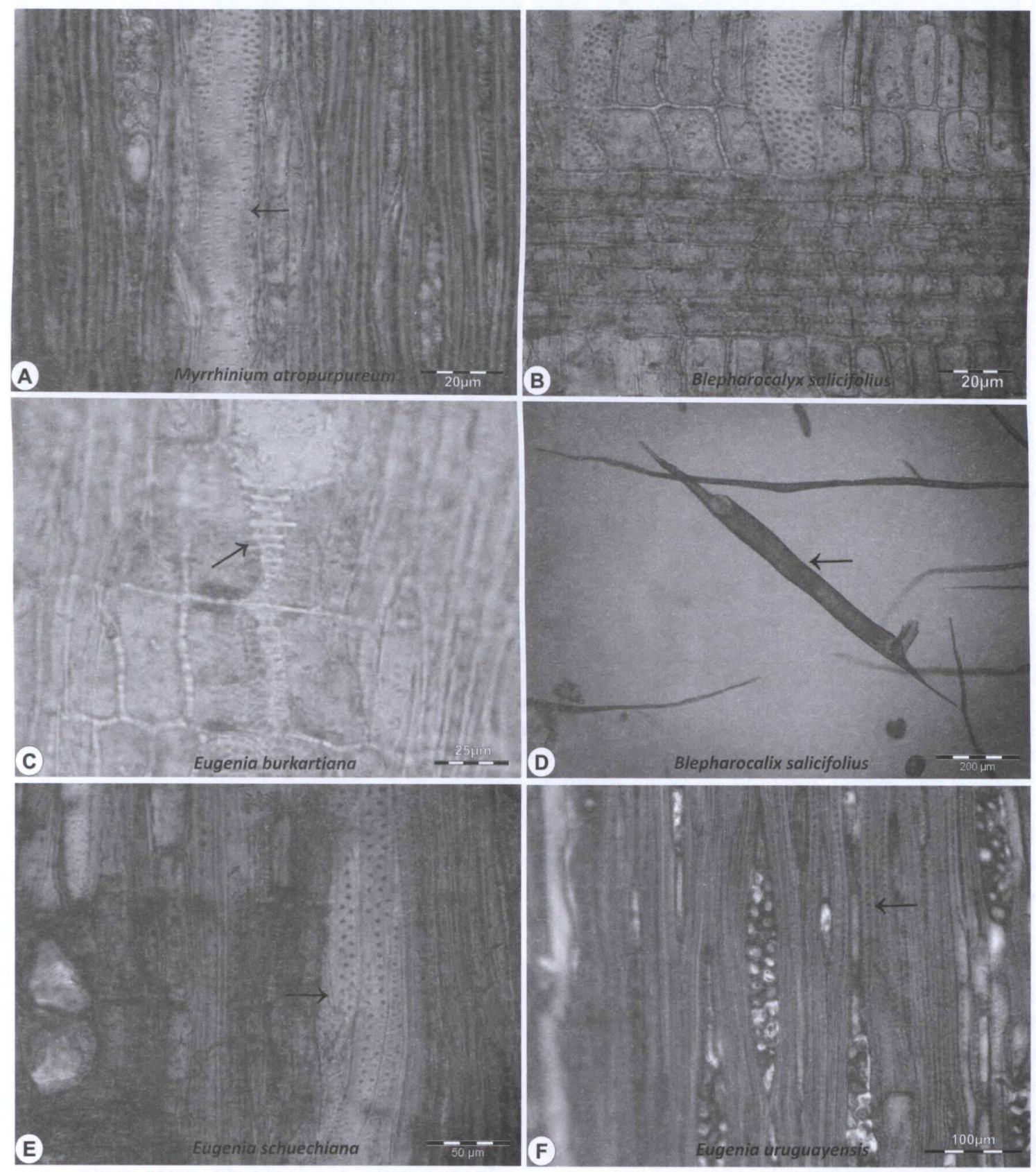

FIGURA 1 - Detalhes anatômicos típicos da anatomia em Myrtaceae. A - Pontoações intervasculares alternas (seta). $\mathrm{B}$ - Raio heterogêneo, com pontoações raio-vasculares semelhantes às intervasculares, restritas às margens. C-Células radiais de paredes disjuntas (seta). D - Elemento vascular com placas de perfuração simples e apêndices em ambas as extremidades (seta). E - Traqueídeos vasicêntricos (seta). F - Fibras com pontoações distintamente areoladas (seta). 

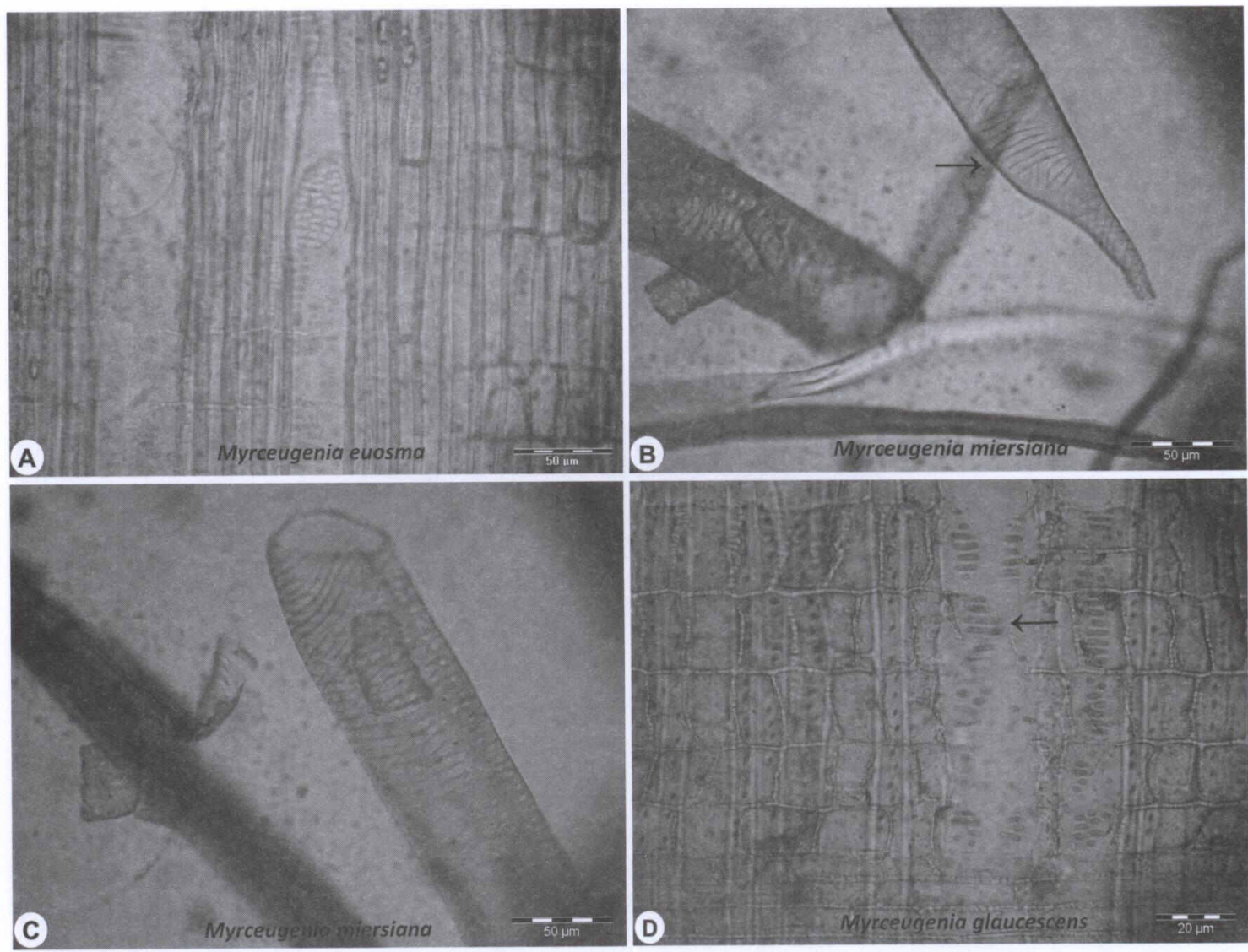

FIGURA 2 - Detalhes anatômicos de Myrceugenia. A - Seção longitudinal radial, mostrando placas de perfuração simples e reticuladas. B, C-Elementos vasculares individualizados, com espessamentos espiralados e placas de perfuração escalariformes (seta) e simples, respectivamente. D - Pontoações raio-vasculares horizontalmente estendidas (seta), em vista radial.

textualmente, a presença, neste grupo, de uma estrutura anatômica bem distinta da que se pode observar em outros gêneros de Myrtaceae.

Schmid \& Baas (1984), em estudo da ocorrência de espessamentos espiralados e placas de perfuração escalariformes na família, encontraram, igualmente, a presença combinada destas duas características apenas em Myrceugenia, o que reforça o valor taxonômico das mesmas. Patel (1995), no entanto, observou pontoações horizontais, placas múltiplas e espessamentos espiralados na madeira de outros gêneros australianos de Myrtaceae. Cabe salientar, ainda, que pontoações horizontalmente estendidas não se restringem a Myrceugenia (Barros \& Callado, 1997; Ovando et al., 2010) e que placas múltiplas, assim como espessamentos espiralados, além de ocorrerem em outros grupos, não se encontram, invariavelmente, em todas as espécies deste gênero, podendo faltar, inclusive, em diferentes indivíduos de uma mesma espécie (Schmid \& Baas, 1984). Estes aspectos, apesar de eventualmente reduzirem a consistência do caráter para a diagnose do gênero, não impedem a sua utilização, ao menos entre os representantes brasileiros da família.

Devido à presença peculiar deste conjunto de características, Myrceugenia mostra-se um gênero a parte, concordando, neste ponto, com o observado pelas análises morfológica (Landrum, 1981) e molecular (Lucas et al., 2005). Cabe, também, a Myrceugenia, o status de maior primitividade entre os gêneros nativos, devido à presença quase constante de pla- 
cas de perfuração escalariformes, caráter considerado por Vliet e Baas (1984) como o mais primitivo na ordem Myrtales. Salvo esta única exceção, não há parâmetro, do ponto de vista da anatomia da madeira, para o reconhecimento de categorias taxonômicas inferiores à tribo, em Myrteae. Dito de outra maneira: nenhuma das diferentes concepções acerca do arranjo interno de Myrteae, discutidas no início deste trabalho, reflete-se na anatomia da madeira.

Também não é possível contestar, com base no presente estudo, a inclusão de Gomidesia em Myrcia, bem como de Hexachlamys em Eugenia, como sugerido por Landrum \& Kawasaki (1997). As características anatômicas observadas em Hexachlamys edulis estão dentro das possibilidades estruturais de Eugenia, o que não surpreende, tendo em vista que a variabilidade anatômica neste gênero é quase tão grande quanto a verificada na tribo Myrteae, a julgar por referências da literatura. Os raios largos e altos da madeira de Gomidesia palustris (Figura 5B) e outras espécies de Gomidesia (Metcalfe \& Chalk, 1972) não são observados nos demais gêneros da família, incluindo Myrcia. Nem todas as espécies de Gomidesia, no entanto, tem raios conspícuos na madeira (Dias-Leme et al., 1995; Andrade et al., 2010), motivo pelo qual não se pode utilizar este caráter como critério para a diagnose do gênero. Em suma: a falta de características anatômicas específicas para os gêneros e grupos taxonômicos superiores limita a atuação da anatomia da madeira em discussões taxonômicas, pelo menos na tribo Myrteae.

Ainda sobre os gêneros, Metcalfe \& Chalk (1972) relacionam para Campomanesia: baixa frequiência de poros $\left(<20 / \mathrm{mm}^{2}\right)$; vasos solitários de diâmetro médio, em linhas oblíquas frouxas; e raios heterogêneos com 4 - 6 células de largura e 1 - 3 fileiras marginais de células quadradas e eretas. Os resultados do presente estudo indicam, todavia, que este conjunto de características nem sempre ocorre e não é restrito ao gênero em questão (Tabela 1,2). Embora não exclusivas de Campomanesia, tais características, quando presentes, são, mesmo assim, importantes sob o ponto de vista taxonômico, por reduzirem o universo de espécies na identificação.

Apesar da grande homogeneidade estrutural e da falta de características específicas para gêneros e grupos taxonômicos superiores, a separação das espécies é possível de ser realizada, embora não em todos os casos. As maiores semelhanças foram observadas entre espécies congêneres, sendo que, por vezes, sequer é possível separá-las, tamanha a homogeneidade estrutural apresentada. Em alguns casos, todavia, observa-se maior similaridade anatômica entre espécies de gêneros distintos, como em Myrcianthes pungens, que se parece mais a Eugenia uniflora do que com Myrcianthes cisplatensis e Myrcianthes gigantea.

Das características qualitativas, $\mathrm{o}$ arranjo do parênquima axial é a que exibe a maior variabilidade (Tabela 1, Figura 3), confirmando o valor taxonômico do caráter na família, em consonância com referências da literatura (Détienne \& Jacquet, 1983; Dias-Leme et al., 1995; Soffiatti \& Angyalossy-Alfonso, 1999). Dos gêneros estudados, Eugenia é o que apresentou a maior variação, em parte pelo maior número de espécies incluídas, resultado que corrobora, igualmente, a já bem conhecida heterogeneidade do grupo (Record \& Hess, 1949). Nem todos os gêneros, todavia, apresentam heterogeneidade no arranjo do parênquima axial, casos de Campomanesia e Myrceugenia, por exemplo (Tabela 1).

Depois do arranjo do parênquima axial, a presença ou não de cristais é a característica qualitativa de maior utilidade para a separação de espécies. O uso deste caráter para fins taxonômicos, todavia, nem sempre é recomendado, devido a sua natureza ocasional, observada em muitas espécies (Wheeler et al., 1989), incluindo Blepharocalyx salicifolius e Myrcianthes pungens, presentemente investigadas (Tabela 1). 

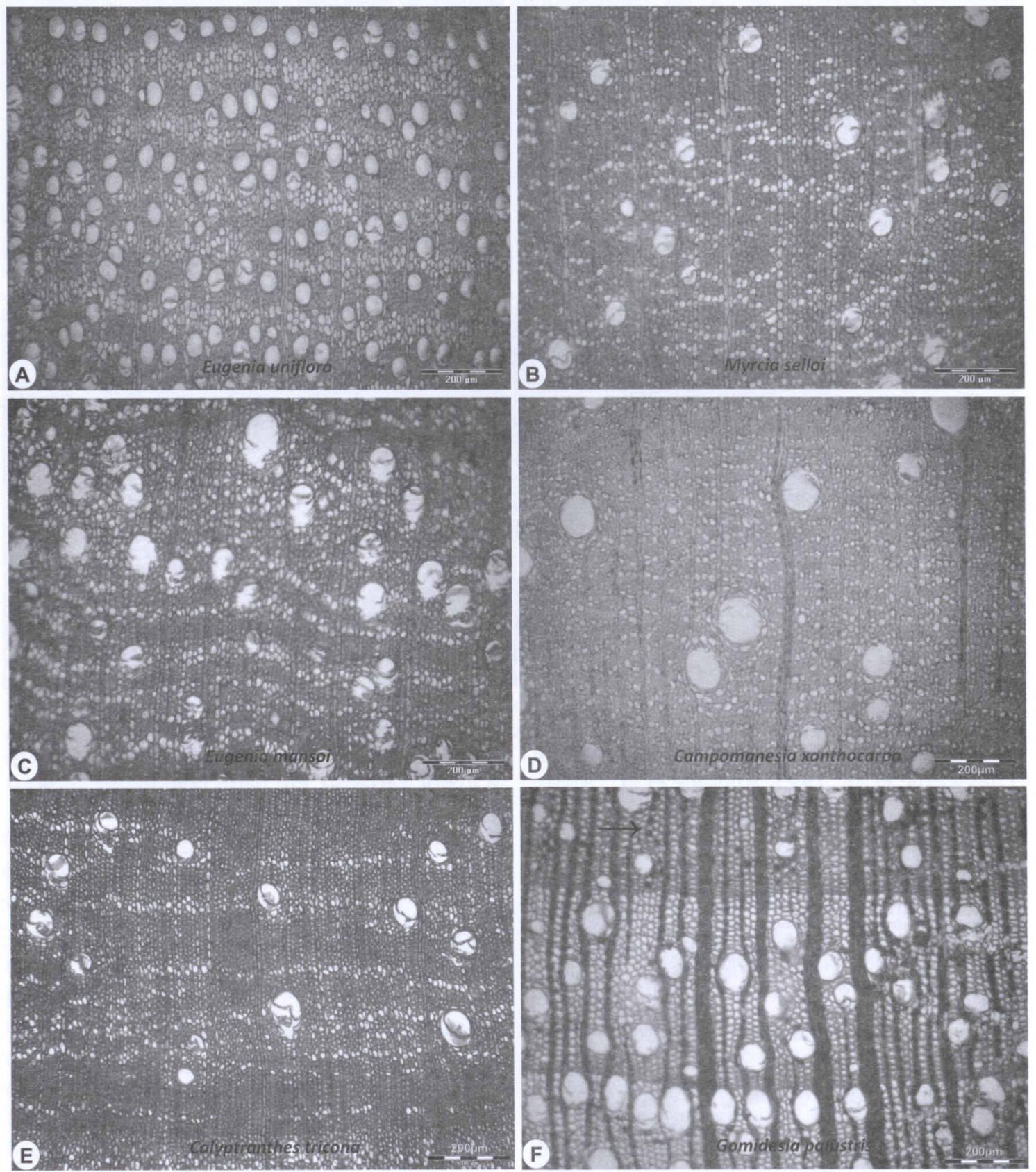

FIGURA 3 - Diversidade no arranjo do parênquima axial. A - Parênquima em faixas tangenciais irregulares, com mais de 3 células de largura. B - Parênquima apotraqueal difuso e difuso-em-agregados (seta), típico da maioria das Mirtáceas. C, E-Parênquima principalmente em linhas ou faixas tangenciais estreitas e descontínuas, com até 3 células de largura. D - Parênquima difuso-em-agregados, com linhas mais ou menos homogeneamente distribuídas tendendo ao padrão escalariforme, observado em algumas espécies de Campomanesia. F - Parênquima apotraqueal difuso e paratraqueal escasso (seta). 

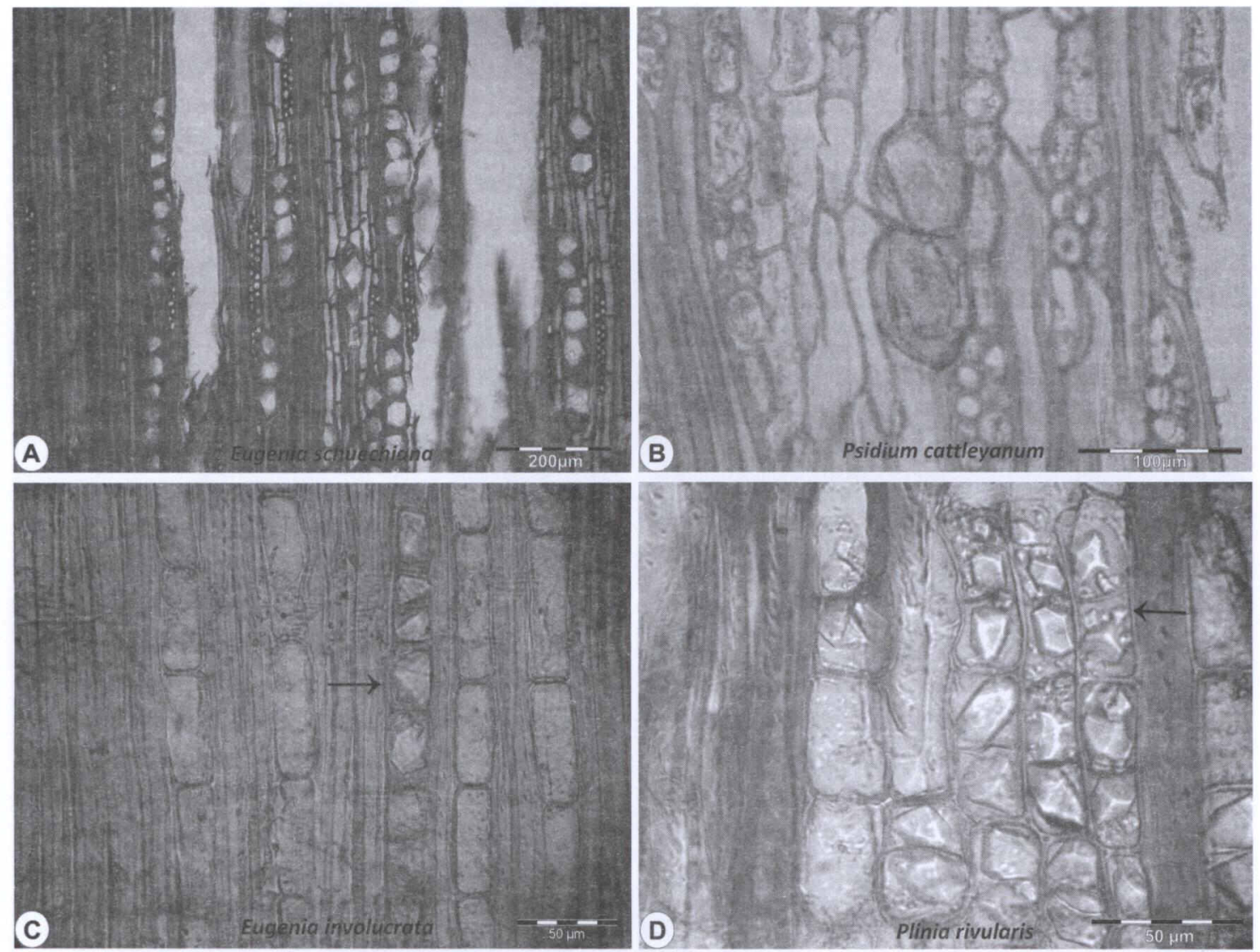

FIGURA 4 - Variabilidade de cristais no parênquima axial. A - Cristais abundantes, em longas séries. B - Série cristalífera curta, composta por dois cristais solitários, dispostos em idioblastos. C - Cristais em câmaras não distendidas (seta). D - Cristais não solitários e de diferentes tamanhos (seta).

menda, por vezes, o uso do caráter para fins taxonômicos, o padrão de distribuição constante, verificado em grupos como Eugenia e Campomanesia (Tabela 1), justificam o emprego criterioso do mesmo, pelo menos nestes casos, sobretudo tendo-se em vista a ausência de aspectos diferenciais mais importantes e a grande homogeneidade estrutural da família.

Além da presença ou ausência de cristais, a ocorrência dos mesmos isoladamente, em grupos ou em idioblastos, bem como o número de unidades por série, são peculiaridades anatômicas merecedoras de observação e que podem auxiliar na separação de espécies. No caso das espécies de Plinia em estudo, por exemplo, observam-se cristais de diferentes tamanhos em uma mesma câmara no parênquima axial, ao contrário do verificado nas demais (Figura 4). A presença de cristais não isolados, todavia, não é exclusividade deste gênero (Dias-Leme et al., 1995).

A presença ou ausência de traqueídeos vasicêntricos e de ornamentações no pontoado intervascular, por outro lado, não é um bom critério para a identificação ou separação segura de espécies em Myrtaceae. A análise destes aspectos revelou que os traqueídeos vasicêntricos não são claramente distinguíveis na maioria das espécies, devido a sua semelhança com fibras, e que as ornamentações, seja pelo seu baixo grau de desenvolvimento ou pela limitação da microscopia óptica, bem como pela escassez e 
tamanho reduzido das pontoações, são, por vezes, de difícil determinação, o que desfavorece o uso do mesmo para fins taxonômicos.

Metcalfe \& Chalk (1972) e Ragonese (1976) já haviam alertado para a dificuldade na determinação da presença de traqueídeos na família - e pelo mesmo motivo. Por vezes, de acordo com o último autor, se pode observar, inclusive, uma transição morfológica entre traqueídeos, fibrotraqueídeos e fibras libriformes. No tocante às pontoações ornamentadas, Vliet \& Baas (1984) e Jansen et al. $(2001,2008)$ consideram o caráter conservativo - e não apenas para as Myrtaceae -, mas para toda a ordem Myrtales. Não de pode dizer, em outras palavras, que não ocorrem ornamentações, pois elas podem não ser visíveis em microscopia ótica. De acordo com Wheeler et al. (1989), o grau de desenvolvimento, bem como a forma e distribuição das ornamentações variam de acordo com o grupo taxonômico. Quando as pontoações são grandes e as ornamentações bem desenvolvidas (ex. Terminalia, Combretaceae), estas são relativamente fáceis de serem vistas em microscopia convencional; quando muito pequenas (ex. Apocynaceae e Rubiaceae), a visualização se torna difícil. Uma determinação mais segura do caráter, neste caso, demanda microscopia eletrônica.

Devido à grande homogeneidade estrutural das Mirtáceas, torna-se necessário recorrer, com frequência, ao exame de caracteres quantitativos para a separação dos diferentes taxa, tarefa que, mesmo assim, nem sempre é possível, sobretudo no caso de espécies de um mesmo gênero (ex. Myrceugenia euosma e Myrceugenia miersiana; Myrcianthes gigantea e Myrcianthes cisplatensis). Dos caracteres investigados, a frequência e diâmetro de poros, bem como a altura de raios, foram os que se mostraram mais úteis para este fim, devido à variabilidade apresentada (Tabela 2). Cabe salientar que ao se utilizar este tipo de característica para fins taxonômicos, deve-se sempre levar em conta a variação decorrente de fatores do meio, especialmente no caso de espécie de regiões distintas (Denardi \& Marchiori, 2005; Marques et al., 2007; Santos \& Marchiori, 2010b).

Para a identificação ou separação das diferentes espécies, além das características de maior variabilidade, discutidas acima, salienta-se a presença de: poros em múltiplos radiais, placas múltiplas, pontoações raio-vasculares horizontais, espessamentos espiralados e raios de largura constante ou com mais de 3 células, devido à ocorrência mais restrita na família. Entre as espécies nativas de anatomia conhecida, apenas Eugenia copacabanensis e Plinia martinellii apresentam poros em múltiplos radiais. Pontoações radialmente estendidas foram observadas na madeira de Myrcia pubipetala (Barros \& Callado, 1997) e Myrcia albotomentosa (Ovando et al., 2010). Placas múltiplas ocorrem somente em Siphoneugena densiflora (Paula et al., 2000), Gomidesia flagellaris e Gomidesia spectabilis (Andrade et al., 2010). Raios com mais de 3 células de largura são referidos para certas espécies de Gomidesia (Andrade et al., 2010), Myrcia (Barros \& Callado, 1997; Barros et al., 2001; Ovando et al., 2010) e Myrceugenia (Ragonese, 1977). A presença de raios de largura constante, bem como de espessamentos espiralados, por sua vez, não consta na literatura de espécies brasileiras.

A largura de raios, apesar de pouco variável (Tabela 2), é aspecto bastante útil para a diferenciação de espécies. Outras características dos raios que podem eventualmente auxiliar nesta tarefa, inclusive dentro de um mesmo gênero, é a composição celular e altura das margens unisseriadas. Calyptranthes concinna, por exemplo, pode ser separada de Calyptranthes tricona pela composição celular das margens: na primeira, verifica-se uma mistura de células eretas e quadradas, ao passo que na segunda há 

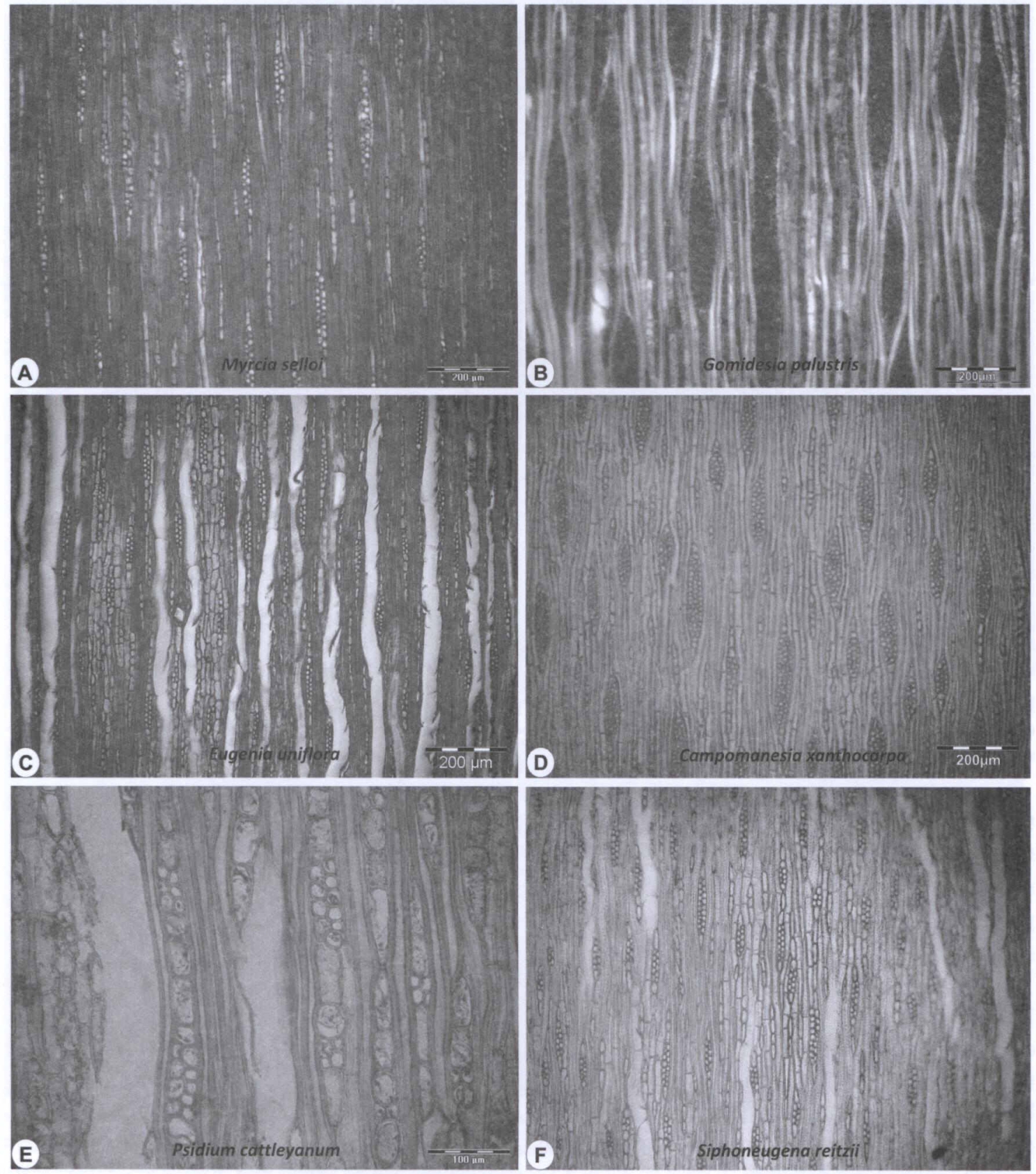

FIGURA 5 - Diversidade na estrutura radial das espécies investigadas. A, C - Raios estreitos, com margens geralmente mais longas do que o corpo central (seta). B, D - Raios largos (> 3 células) e em dois tamanhos distintos, com margens unisseriadas mais curtas do que o corpo central. E - Raio com largura constante e frequente fusão axial. F - Raios estreitos, com margens unissseriadas geralmente mais curtas do que o corpo central. 

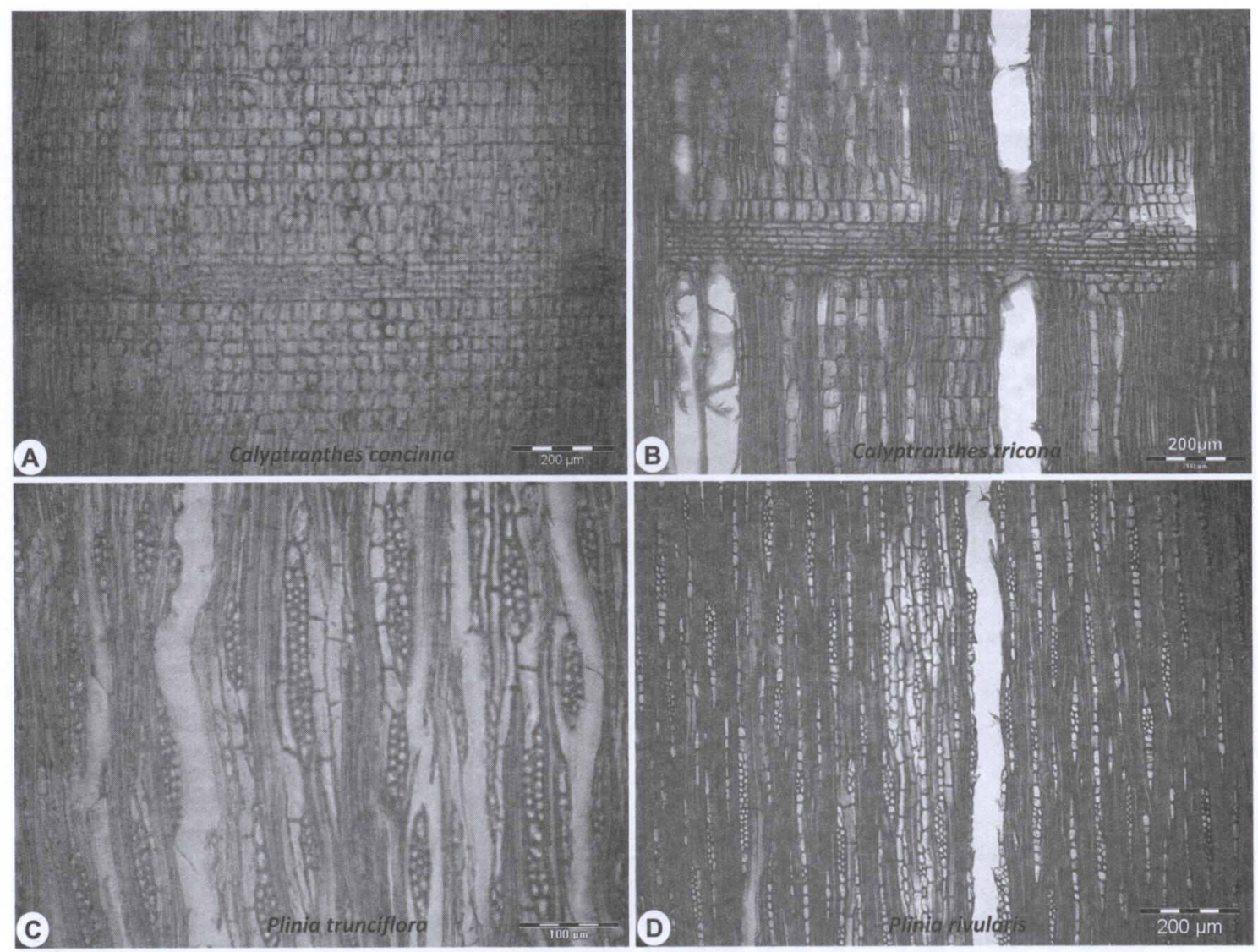

FIGURA 6 - Variabilidade na composição e altura das margens de raios. A - Margens compostas por uma mistura de células procumbentes, quadradas e eretas. B, D - Margens de células quase exclusivamente eretas. C - Margens com células principalmente quadradas e eretas.

um claro predomínio de células eretas (Figura 6A,B). Plinia trunciflora, por sua vez, separase de Plinia rivularis pelas margens unisseriadas geralmente mais curtas do que o corpo central (Figura 6C,D).

A altura das séries de parênquima axial (células), por outro lado, nãoé, geralmente, um bom critério, devido à baixa variabilidade apresentada e à sobreposição de valores (Tabela 2), sobretudo se considerada apenas a altura predominante na madeira, que é de 4-8 células, na grande maioria das espécies.

\section{REFERÊNCIAS BIBLIOGRÁFICAS}

ANDRADE, I.M.; LONGUI, E.L; SANTINI JUNIOR, L;SOBRAL, E.S.; AGUIAR, O.T.;
FLORSHEIM, S.M.B; LIMA, I.L. Anatomia comparada do lenho de quatro espécies de Gomidesia spp. Berg (Myrtaceae) do Parque Estadual Carlos Botelho - SP. $4^{\circ}$ Seminário de Iniciação Científica do Instituto Florestal, 2010.

BARROS, C.F.; CALLADO, C.H. Madeiras da Mata Atlântica. Anatomia do lenho de espécies ocorrentes nos remanescentes florestais do estado do Rio de Janeiro, Brasil. Rio de Janeiro: Instituto de Pesquisas Jardim Botânico do Rio de Janeiro, 1997. 86 p.

BARROS, C.F. et al. Madeiras da Mata Atlântica. Anatomia do lenho de espécies ocorrentes nos remanescentes florestais do estado do Rio de Janeiro, Brasil. Rio de Janeiro: Instituto de Pesquisas Jardim Botânico do Rio de Janeiro, 2001. $94 \mathrm{p}$.

BARROSO, G.M. Sistemática de Angiospermas do Brasil. Viçosa: UFV, 1991. 377 p. 


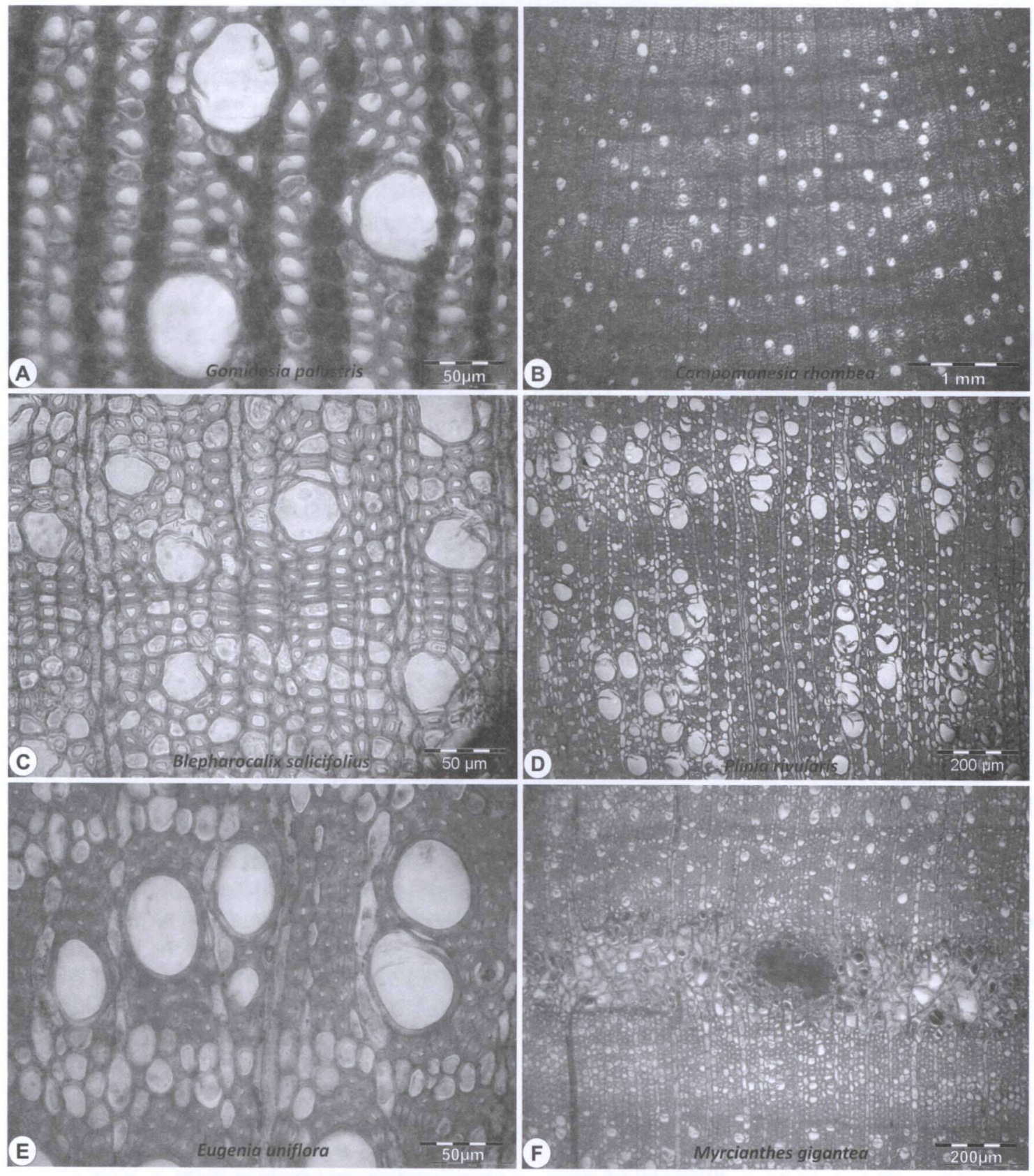

FIGURA 7 - Detalhes anatômicos da seção transversal das madeiras investigadas. A - Fibras de paredes finas. B - Poros exclusivamente solitários, sem padrão definido de organização, e limite de anéis de crescimento com zonas fibrosas estreitas. C - Fibras de paredes espessas, achatadas no limite de anel de crescimento. Notar, também, a presença de poros poligonais, caráter freqüente em espécies com vasos de pequeno diâmetro. D - Poros solitários e em curtos múltiplos radiais. E - Fibras de paredes muito espessas e poros circulares a ovais. F - Aspecto geral de uma mácula medular, com canal intercelular associado (centro). 
BERG, O. Revisio Myrtacearum Americae. Linnaea, v. 27 , p. 1-472. 1855-56.

BERG. O. Myrtaceae. In: MARTIUS, C.F.P. von. Flora Brasiliensis, v. 14, p. 1 - 655. 1857-59.

BRIGGS, B.G.; JONHSON, L.A.S. Evolution in the Myrtaceae - evidence from inflorescence structure. Proceedings of the Linnean Society of New South Wales, n. 102, p. 157-256, 1979.

COSTA, I.R. Estudos cromossômicos em espécies de Myrtaceae Juss. no sudeste do Brasil. 2004. $80 \mathrm{f}$. Dissertação de Mestrado - Universidade Estadual de Campinas (UNICAMP), Campinas, 2004.

COSTA, I.R. Estudos evolutivos em Myrtaceae: aspectos citotaxonômicos e filogenéticos em Myrteae, enfatizando Psidium e gêneros relacionados. 2009. 235 f. Tese (Doutorado) - Universidade Estadual de Campinas, Campinas, 2009.

DE CANDOLLE, A.P. Myrtaceae. In: Prodromus Systematis Naturalis Regni Vegetabilis. v. 3, p. 207-296, 1828.

DENARDI, L.; MARCHIORI, J.N.C. Anatomia ecológica da madeira de Blepharocalyx salicifolius (H. B. K.) Berg. Ciência Florestal, Santa Maria, v. 15, n. 2, p. 119-127, 2005.

DÉTIENNE, P.; JACQUET, P. Atlas d'identification des bois de l'Amazonie et des regions voisines. Centre Technique Forestier Tropical, Nogentsur-Marne, 1983. 640 p.

DIAS-LEME, C.L.; GASSON, P.; LUGHADA, E.N. Wood anatomy of four Myrtaceae genera in the subtribe Myciinae from South America. IAWA Bulletin, n. 16, p. 87-95, 1995.

GOVAERTS, R. et al. World Checklist of selected plant families - Myrtaceae. Kew Publishing, Royal Botanic Gardens, Kew. 2008.

JANSEN, S; BAAS, P; SMETS, E. Vestured pits: their occurrence and systematic importance in Eudicots. Taxon, v. 50, n. 1, p. 135-167, 2001.

JANSEN, S.; PLETSERS, A.; RABAEY, D.; LENS, F. Vestured pits: a diagnostic character in the secondary xylem of Myrtales. Journal of Tropical Forest Science, v. 20, n. 4, p. 328-339, 2008.

JOHNSON, L.A.S.; BRIGGS, B.G. Myrtales and Myrtaceae: a phylogenetic analysis. Annals of the Missouri Botanical Garden, v. 71, p. 700756, 1984.

LANDRUM, L.R. A monograph of the genus $M y r-$ ceugenia. Flora Neotropica, n. 29, p. 1-137, 1981.
LANDRUM, L.R.; KAWASAKI, M.L. The genera of Myrtaceae in Brasil: an illustrated synoptic treatment and identification keys. Brittonia, n. 49, p. 508-536, 1997.

LUCAS, E.J. et al. Phylogenetic patterns in the fleshyfruited Myrtaceae - preliminary molecular evidence. Plant Systematics and Evolution, v. 251, p. 35-51, 2005.

MARCHIORI, J.N.C. Anatomia da madeira de Eugenia involucrata DC. (Myrtaceae). Ciência e Natura, Santa Maria, v. 6, p. 127-136, 1984a.

MARCHIORI, J.N.C. Anatomia descritiva do lenho de Feijoa sellowiana Berg. Ciência e Natura, Santa Maria, v. 6, p. 117-125, 1984b.

MARCHIORI, J.N.C. Anatomia descritiva da madeira do murtilho Myrrhinium loranthoides (Hook. et Arn.) Burret (Myrtaceae). Revista do Centro de Ciências Rurais, Santa Maria, v. 14, n. 1, p. 43-50, 1984c.

MARCHIORI, J.N.C. Estudo anatômico da madeira de sete-capotes, Campomanesia guazumifolia (Camb.) Berg. (Myrtaceae). Ciência Rural, Santa Maria, v. 28, n. 1, p. 47-51, 1998.

MARCHIORI, J.N.C.; BRUM, E.T. Anatomia da madeira do guamirim-facho, Calyptranthes concinna DC. (Myrtaceae). Ciência Rural, Santa Maria, v. 27, n. 2, p. 217-222, 1997.

MARCHIORI, J.N.C.; MUÑIZ, G.I.B. Estudo anatômico da madeira de Myrciaria tenella (DC.) Berg. Ciência e Natura, Santa Maria, v. 9, p. 87-95, 1987a.

MARCHIORI, J.N.C.; MUÑIZ, G.I.B. Anatomia descritiva da madeira de Myrceugenia myrtoides Berg. Ciência e Natura, Santa Maria, v. 9, p. 113-120, 1987b.

MARCHIORI, J.N.C.; MUÑIZ, G.I.B. Estudo anatômico da madeira de Myrceugenia glaucescens (Camb.) Legr. et Kaus. Ciência e Natura, Santa Maria, v. 10, p. 105-113, 1988.

MARCHIORI, J.N.C.; SANTOS, S.R. Anatomia do xilema secundário de Eugenia mansoi O. Berg (Myrtaceae). Balduinia, n. 16, p. 6-12, 2009a.

MARCHIORI, J.N.C.; SANTOS, S.R. Descrição anatômica da madeira de Myrcia bombycina (O. Berg) Niedenzu (Myrtaceae). Balduinia, n. 17, p. 17-22, 2009b.

MARCHIORI, J.N.C.; SANTOS, S.R. Estudo anatômico do lenho de Psidium cattleianum Sabine (Myrtaceae). Balduinia, n. 18, p. 15-19, 2009c. 
MARCHIORI, J.N.C.; SANTOS, S.R. Anatomia do xilema secundário de Eugenia mansoi O. Berg (Myrtaceae). Balduinia, n. 16, p. 6-12, 2009a.

MARCHIORI, J.N.C.; SANTOS, S.R. Anatomia do lenho de Plinia trunciflora (O. Berg) Kausel (Myrtaceae). Balduinia, n. 20, p. 26-30, 2010a.

MARCHIORI, J.N.C.; SANTOS, S.R. Anatomia da madeira de duas espécies de Eugenia L. (Myrtaceae). Balduinia, Santa Maria, n. 21, p. 15-21, 2010b.

MARCHIORI, J.N.C.; SANTOS, S.R. Anatomia das madeiras de Campomanesia aurea O. Berg e Eugenia myrcianthes Niedenzu (Myrtaceae). Balduinia, Santa Maria, n. 22, p. 23-30, 2010c.

MARCHIORI, J.N.C.; SOBRAL, M. Dendrologia das Angiospermas. Myrtales. Santa Maria: Ed. da UFSM, 1997. 304 p.

MARQUES, P.A. et al. Anatomia do lenho de três espécies de Eugenia L. (Myrtaceae) de mata e restinga. Revista Brasileira de Biociências, v. 5, p. 801-803, 2007.

METCALFE, C.R.; CHALK, L. Anatomy of the Dicotyledons. Oxford: Clarendon Press, 1972, 1500 p.

McVAUGH, R. The genera of American Myrtaceae, an interim report. Taxon, v. 17, n. 8, p. 354-418, 1968.

NIEDENZU, F. Myrtaceae. In: ENGLER, A.; PRANTL, K. Die natürlichen Pflanzenfamilien, v. 3, p. 57-105, 1893.

OVANDO, P.C. et al. Anatomia do lenho de Myrcia albotomentosa DC. e Myrcia multiflora (Lam.) DC. (Myrtaceae). $4^{\circ}$ Seminário de Iniciação Científica do Instituto Florestal, 2010.

PATEL, R.N. Wood anatomy of the dicotyledons indigenous to New Zealand. 25 Myrtaceae subfam. Myrtoideae (part 1). New Zealand Journal of Botany, v. 33, p. 541-555, 1995.

PAULA, J.E.; JUNIOR, F.G.S.; SILVA, A.P.P. Caracterização anatômica de madeiras nativas de matas ciliares do centro-oeste brasileiro. Scientia Forestalis, v. 58, p. 73-89, 2000.

RAGONESE, A.M. Consideraciones sobre el problema de la classificación de los elementos traqueales no perfurados de las Dicotiledôneas y en especial de algunas Mirtáceas. Darwiniana, San Isidro, v. 20, n.3/4, p. 476-490, 1976.

RAGONESE, A.M. Caracteres anatómicos del parénquima radial y axial en leño de las Mirtáceas. Darwiniana, San Isidro, v. 21, n. 1, p. 27-41, 1977.

RECORD, S.J.; HESS R.W. Timbers of the New World. New Haven: Yale University Press, 1949. $640 \mathrm{p}$.

SANTOS S.R.; MARCHIORI, J.N.C. Anatomia do xilema secundário de Myrceugenia euosma (O. Berg) D. Legrand. Balduinia, n. 16, p. 24-29, 2009a.

SANTOS, S.R.; MARCHIORI, J.N.C. Anatomia da madeira de Eugenia uniflora L. (Myrtaceae). Balduinia, n. 17, p. 11-16, 2009b

SANTOS, S.R.; MARCHIORI, J.N.C. Caracterização microscópica do lenho de Campomanesia xanthocarpa O. Berg (Myrtaceae). Balduinia, n. 18 , p. 10-14, 2009c.

SANTOS, S.R.; MARCHIORI, J.N.C. Anatomia da madeira de Myrcianthes pungens (O. Berg) D. Legrand (Myrtaceae). Balduinia, n. 19, p. 2530, 2009d.

SANTOS, S.R.; MARCHIORI, J.N.C. Anatomia do lenho de Calyptranthes tricona D. Legrand (Myrtaceae). Balduinia, n. 20, p. 21-25, 2010a.

SANTOS, S.R.; MARCHIORI, J.N.C. Tendências anatômicas na flora sul-rio-grandense. 1 - Elementos vasculares. Balduinia, n. 21, p. 01-14, $2010 b$.

SANTOS, S.R.; MARCHIORI, J.N.C. Anatomia da madeira de duas espécies de Myrcia DC., nativas no Rio Grande do Sul. Balduinia, n. 21, p. 22-28, 2010c.

SANTOS, S.R.; MARCHIORI, J.N.C. Anatomia das madeiras de Eugenia burkartiana (D. Legrand) D. Legrand e Myrciaria cuspidata O. Berg, duas Myrtoídeas nativas no Rio Grande do Sul. Balduinia, n. 22, p. 15-22, 2010d.

SANTOS, S.R.; MARCHIORI, J.N.C. Caracterização anatômica da madeira de Siphoneugena reitziii D. Legrand (Myrtaceae). Balduinia, n. 23, p. 21-26, 2010e.

SANTOS, S.R.; MARCHIORI, J.N.C. Estudo anatômico do lenho de Myrcianthes cisplatensis (Camb.) O. Berg (Myrtaceae). Balduinia, n. 24, p. 23-28, 2010f.

SANTOS, S.R.; MARCHIORI, J.N.C. Anatomia da madeira de Campomanesia rhombea O. Berg (Myrtaceae). Balduinia, n. 25, p. 16-21, 2010g.

SANTOS, S.R.; MARCHIORI, J.N.C. Estudo anatômico do lenho de Eugenia schuechiana $\mathrm{O}$. Berg (Myrtaceae). Balduinia, n. 26, p. 27-32, 2011a. 
SANTOS S.R.; MARCHIORI, J.N.C. Anatomia da madeira de Myrceugenia miersiana (Gardner) D. Legrand et Kausel. Balduinia, n. 27, p. 2026, 2011b.

SANTOS, S.R.; MARCHIORI, J.N.C. Estudo anatômico do lenho de Eugenia hiemalis Cambess. (Myrtaceae). Balduinia, n. 31 p. 27 32, 2011c.

SCHMD, R. Comparative anatomy and morphology of Psiloxylon and Heteropyxis, and the subfamilial and tribal classification of Myrtaceae. Taxon, n. 29, p. 559-595, 1980.

SCHMID, R.; BAAS, P. The occurrence of scalariform perforation plates and helical thickenings in wood of Myrtaceae. IAWA Bulletin, v. 5, n. 3, p. 197-215, 1984.

SOBRAL, M. A família Myrtaceae no Rio Grande do Sul. São Leopoldo: Unisinos, 2003. 215 p.

SOFFIATTI, P.; ANGYALOSSY-ALFONSO, V.A. Estudo anatômico comparativo do lenho e da casca de duas espécies de Eugenia L. (Myrtaceae). Revista Brasileira de Botânica, São Paulo, v. 22, n. 2, p. 175-184, 1999.

VLIET, G.J.C. van; BAAS, P. Wood anatomy and classification of the Myrtales. Annals of the Missouri Botanical Garden, n. 71, p. 783-800, 1984.

WHEELER, E.A.; BAAS, P.; GASSON, P.E. IAWA list of microscopic features for hardwood identification. IAWA Bull., v.10, n. 3, p. 218359, 1989.

WILSON, P.G.; O'BRIEN, M.M.; GADEK, P.A.; QUINN, C.J. Myrtaceae revisited: a reassessment of infrafamilial groups. American Journal of Botany, v. 88, n. 11, p. 2013-2015, 2001.

WILSON, P.G.; O’BRIEN, M.M.; HESLEWOOD, M.M.; QUINN, C.J. Relationship within Myrtaceae sensu lato based on matk phylogeny. Plant Systematics and Evolution, v. 251, p. 319, 2005.

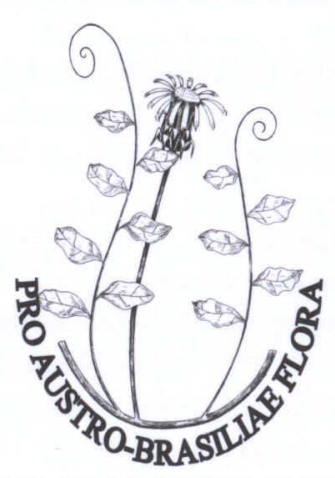

Revista científica do Herbário do Departamento de Ciências Florestais da Universidade Federal de Santa Maria, Balduinia visa a contribuir para a Botânica sul-brasileira com publicações originais nas áreas de Taxonomia Vegetal, Fitogeografia e Anatomia da Madeira. O nome do periódico presta merecida homenagem a Balduíno Rambo, um dos mais importantes botânicos e fitogeógrafos brasileiros do século vinte.

Solicita-se permuta / Exchange desired 